\title{
Utility and lower limits of frequency detection in surface electrode stimulation for somatosensory brain-computer interface in humans
}

\author{
Daniel R. Kramer, MD, ${ }^{1,2}$ Krista Lamorie-Foote, BA, ${ }^{3}$ Michael Barbaro, BA, ${ }^{3}$ Morgan B. Lee, BS, ${ }^{3}$ \\ Terrance Peng, MPH, ${ }^{3}$ Angad Gogia, BS, ${ }^{3}$ George Nune, MD, ${ }^{4}$ Charles Y. Liu, MD, PhD, ${ }^{1,2}$ \\ Spencer S. Kellis, $\mathrm{PhD},{ }^{2,5,6}$ and Brian Lee, MD, $\mathrm{PhD}^{1,2}$
}

Departments of ${ }^{1}$ Neurosurgery and ${ }^{4}$ Neurology, ${ }^{2}$ Neurorestoration Center, and ${ }^{3}$ Keck School of Medicine, University of Southern California, Los Angeles; and ${ }^{5}$ Department of Biology and Biological Engineering and ${ }^{6}$ Tianqiao and Chrissy Chen Brain-Machine Interface Center, California Institute of Technology, Pasadena, California

\begin{abstract}
OBJECTIVE Stimulation of the primary somatosensory cortex (S1) has been successful in evoking artificial somatosensation in both humans and animals, but much is unknown about the optimal stimulation parameters needed to generate robust percepts of somatosensation. In this study, the authors investigated frequency as an adjustable stimulation parameter for artificial somatosensation in a closed-loop brain-computer interface $(\mathrm{BCl})$ system.

METHODS Three epilepsy patients with subdural mini-electrocorticography grids over the hand area of S1 were asked to compare the percepts elicited with different stimulation frequencies. Amplitude, pulse width, and duration were held constant across all trials. In each trial, subjects experienced 2 stimuli and reported which they thought was given at a higher stimulation frequency. Two paradigms were used: first, 50 versus $100 \mathrm{~Hz}$ to establish the utility of comparing frequencies, and then $2,5,10,20,50$, or $100 \mathrm{~Hz}$ were pseudorandomly compared.
\end{abstract}

RESULTS As the magnitude of the stimulation frequency was increased, subjects described percepts that were "more intense" or "faster." Cumulatively, the participants achieved $98.0 \%$ accuracy when comparing stimulation at 50 and 100 $\mathrm{Hz}$. In the second paradigm, the corresponding overall accuracy was $73.3 \%$. If both tested frequencies were less than or equal to $10 \mathrm{~Hz}$, accuracy was $41.7 \%$ and increased to $79.4 \%$ when one frequency was greater than $10 \mathrm{~Hz}(p=0.01)$. When both stimulation frequencies were $20 \mathrm{~Hz}$ or less, accuracy was $40.7 \%$ compared with $91.7 \%$ when one frequency was greater than $20 \mathrm{~Hz}(p<0.001)$. Accuracy was $85 \%$ in trials in which $50 \mathrm{~Hz}$ was the higher stimulation frequency. Therefore, the lower limit of detection occurred at $20 \mathrm{~Hz}$, and accuracy decreased significantly when lower frequencies were tested. In trials testing $10 \mathrm{~Hz}$ versus $20 \mathrm{~Hz}$, accuracy was $16.7 \%$ compared with $85.7 \%$ in trials testing $20 \mathrm{~Hz}$ versus $50 \mathrm{~Hz}(\mathrm{p}<0.05)$. Accuracy was greater than chance at frequency differences greater than or equal to $30 \mathrm{~Hz}$.

CONCLUSIONS Frequencies greater than $20 \mathrm{~Hz}$ may be used as an adjustable parameter to elicit distinguishable percepts. These findings may be useful in informing the settings and the degrees of freedom achievable in future $\mathrm{BCl}$ systems.

https://thejns.org/doi/abs/10.3171/2019.11.FOCUS19696

KEYWORDS somatosensation; cortical stimulation; brain-computer interface; $\mathrm{BCl}$; sensory feedback control; electrocorticography; ECoG; frequency

$\mathrm{F}$ OR patients with loss of function due to stroke or paralysis, the restoration of somatosensation has implications both for motor restoration ${ }^{17,24}$ through

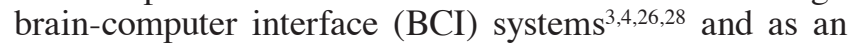
independent aid for monitoring injury, pressure, and internal organ states. Direct electrical stimulation of the pri- mary somatosensory cortex (S1) is a promising technique for generating artificial somatosensation in humans, having yielded reliable and safe outcomes. ${ }^{2,5,13,14,16}$ Given the success of initial studies, the next step is to understand the limitations and parameters involved in leveraging artificial sensation in a closed-loop BCI system.

ABBREVIATIONS BCI = brain-computer interface; $\mathrm{ECOG}=$ electrocorticography; $\mathrm{EMU}=$ epilepsy monitoring unit; NHP = nonhuman primate; $\mathrm{S} 1$ = primary somatosensory cortex.

SUBMITTED September 14, 2019. ACCEPTED November 4, 2019.

INCLUDE WHEN CITING DOI: 10.3171/2019.11.FOCUS19696. 
TABLE 1. Participant demographics

\begin{tabular}{cllrcc}
\hline Subject & \multicolumn{1}{c}{ Seizure Foci } & Radiographic Abnormalities & \multicolumn{1}{c}{ Epilepsy Duration (yrs) } & Age (yrs), Sex & Dominant Hand \\
\hline S08 & Lt amygdala \& hippocampus & Lt mesial temporal sclerosis & 3 & $21, \mathrm{~F}$ & $\mathrm{Rt}$ \\
\hline S10 & Lt mesial temporal & Lt mesial temporal sclerosis & 45 & $50, \mathrm{~F}$ & $\mathrm{Rt}$ \\
\hline S14 & Rt temporal & Prior surgery for rt parietal cavernous malformation & 3 & $25, \mathrm{~F}$ & $\mathrm{Rt}$ \\
\hline
\end{tabular}

Epilepsy patients underwent subdural ECoG implantation to localize their seizure foci, and an ECoG grid was placed over S1.

Studies in nonhuman primates (NHPs) with cortical stimulation in the S1 region have produced performance results comparable to those of real sensation in behavioral tasks. ${ }^{18,27}$ Trained rhesus monkeys in an active exploration task are able to use artificial stimulation to discriminate between periodic pulse trains of intracortical microstimulation. ${ }^{20}$ In a vibrational "flutter" discrimination task, monkeys achieved nearly the same degree of accuracy (80\% accuracy with artificial stimulation vs $89 \%$ for mechanical stimulation) receiving either a physical stimulus or a cortical stimulus of 10 to $30 \mathrm{~Hz} .^{22,23}$ Motor BCI has also shown performance improvements when paired with cortical stimulation feedback in a closed-loop BCI system. . $^{12,19,26}$

Preliminary work with NHPs has investigated the effects of electrode configuration and stimulation parameters on the detectability and discernibility of percepts arising from cortical stimulation..$^{10,11}$ However, despite the information gained from animal studies, the range of parameter changes that result in functionally useful percepts in humans is not clear. The frequency component of the stimulation pulse train is of particular interest as it has been shown, in humans, to be a parameter that can be altered independently, and may play a role in the coding of different types of sensory percepts ${ }^{16}$ or alter the perceived intensity of a stimulus. ${ }^{6,16}$ NHPs with microelectrodes were able to differentiate between sensory percepts arising from frequencies as low as 6 and $10 \mathrm{~Hz},{ }^{22}$ suggesting $10 \mathrm{~Hz}$ as a lower limit of detection (it is not possible to tell if the monkeys felt a percept at $6 \mathrm{~Hz}$ or learned to interpret the absence of sensation as the lower frequency). The justnoticeable difference, that is, the lower limit of discerning between two frequencies at $75 \%$ accuracy, was $4.57 \mathrm{~Hz}$, similar to that with mechanical trials $(3.97 \mathrm{~Hz}){ }^{22}$

Based on these prior studies, it is reasonable to hypothesize that altering stimulation frequency will yield discernable percepts for humans as well. Indeed, while studies in humans have mostly focused on the effects of varying the amplitude of stimulation, ${ }^{2,5}$ frequency has been successfully altered in somatosensory BCI systems. A recent high-density electrocorticography (ECoG) study modulated frequencies from 2 to $100 \mathrm{~Hz}$ sequentially and suggested a lower limit of detection around $20 \mathrm{~Hz} \cdot{ }^{16}$ However, this was derived from the response generated by subjects and not in a paradigm of direct comparison. Another ECoG study did attempt to compare frequencies among $50,65,75$, and $100 \mathrm{~Hz}$ in limited pair combinations and noted that participants could differentiate between evoked somatosensation. ${ }^{9}$ These studies suggest that changing frequency alone is discernable to subjects; however, 2 important aspects are necessary to clarify use of frequency as a consistent and functionally useful parameter: first, to demonstrate that frequency is indeed a reliable parameter to provide feedback to a BCI participant over repeat stimulations, and second, to assess the lower threshold of detection.

Here, we assess the reliability of perceived changes in artificial somatosensation following changes in stimulation frequency and the detection thresholds of percepts generated with low stimulation frequencies. We investigated these properties of stimulation frequency using 2 experimental paradigms designed to compare frequencies both coarsely and with smaller differences between the frequencies. With this approach, we expand on the results of earlier studies and hope to provide insights into how frequency might be best utilized in a closed-loop BCI system.

\section{Methods}

\section{Subjects and Implantation}

Three participants (S08, S10, and S14) with intractable epilepsy undergoing subdural ECoG implantation for seizure localization, with access to $\mathrm{S} 1$, were recruited to this study (Table 1). This study was approved by the University of Southern California institutional review board, and all subjects provided written informed consent. Participants were without deficits in somatosensation and were of normal intelligence following preoperative neuropsychiatric testing. To identify the seizure focus, a craniotomy was performed for subdural ECoG grid placement, which also had access to the hand representation of S1. S08 had a seizure focus in the left hippocampus and amygdala, as well as sclerosis in the left mesial temporal lobe. S10 had a seizure focus in the left mesial temporal lobe, along with sclerosis in the same region. S14 had a seizure focus in the right parietal lobe and a history of surgery for a right parietal cavernous malformation; both regions were separate and distinct from S1 (Table 1).

Before surgery, anatomical landmarks were used to identify the hand representation of the motor cortex and the corresponding hand region in S1 based on preoperative MRI findings. While our surgical protocol has been previously described in detail, ${ }^{16}$ briefly, a frontotemporoparietal craniotomy was performed. The S1 hand region was not always directly visualized, and the implanted ECoG grids were placed over this region using intraoperative navigation. For S08 and S10, grids were high-density, "mini"-ECoG grids with 2 -mm contacts, with a 1.2-mm exposed surface of platinum-iridium electrodes between silastic sheeting, spaced $3 \mathrm{~mm}$ apart (FG64C-MP03, Ad-Tech Medical Instrument Corp.). For 
S14, ECoG with standard spacing was implanted with 4-mm contacts, with a 2.4-mm exposed surface, spaced $1 \mathrm{~cm}$ apart (AU4X5P2, Integra Life Sciences Corp.). Following standard protocol, the dura was sutured closed, the bone was replaced, and the scalp was closed, with the lead tails tunneled out of the skin for attachment to the recording equipment and the stimulator. As part of the clinical monitoring, patients were placed in the epilepsy monitoring unit (EMU).

\section{Experimental Setup}

All testing occurred in the EMU on hospital day 6 or 7 , after participants resumed their antiepileptic medications and under direct supervision by the treating epileptologist. While the participants were in the EMU, functional electrode locations were mapped with intracortical stimulation. The epileptologist stimulated the cortex using the FDA-approved Natus stimulator (Natus Neurology Inc.). Stimulation of electrode pairs was done with the following parameters: frequency of $50 \mathrm{~Hz}$, pulse width of $250 \mu \mathrm{sec}$, duration of 1 second. The amplitude ranged from $0.5 \mathrm{~mA}$ to $12 \mathrm{~mA}$ at the discretion of the epileptologist. Generally, stimulation started at $2 \mathrm{~mA}$ and was steadily increased until one of the following categorizations was noted: "sensory" (somatosensation without any involuntary muscle movement), "motor" (visible motion, the feeling of motion without visible motion was considered proprioceptive sensory), "mixed motor-sensory" (both motion and somatosensation), and "no response" (when the amplitude reached $12 \mathrm{~mA}$ without a response). If concern for epileptiform activity was noted by the epileptologist (e.g., afterdischarges) the amplitude was stopped prior to reaching $12 \mathrm{~mA}$. Once an electrode pair was determined to have somatosensory percepts only, the response was retested 25 times with the same parameters to ensure stability. If more than 1 pair met these criteria, the electrode pairs with a dermatome on the ventral side of the hand and those that occurred on the thumb, index, or middle finger were chosen.

To test discrimination between frequencies, subjects performed a target acquisition task: they moved the hand contralateral to the implanted ECoG grid over 2D targets and received intracortical stimulation over each target as the only feedback; following stimulation, they verbalized which target had the higher frequency. The frequencies used in these trials were dependent on which paradigm was tested. In the first paradigm, frequencies of 50 and $100 \mathrm{~Hz}$ were chosen for each target in a pseudorandom fashion to establish that reliable detection could be obtained between two frequencies for the purpose of locating hidden targets. Second, frequencies of 2, 5, 10, 20, 50, and $100 \mathrm{~Hz}$ were compared in a pseudorandom fashion to establish the lower and upper limits of detection and basic parameters for noticeable differences between frequencies. Paradigm 1 was performed on S08 and S10, with 50 trials each, and paradigm 2 was performed on S10 (50 trials) and S14 (25 trials). Due to limited testing time in the EMU, we were unable to perform all study paradigms in each participant. Statistical analysis was carried out with MATLAB software (MathWorks). Fisher's exact test was used to compare responses.

\section{Results}

Grid locations were assessed by fusing a postoperative CT scan to a preoperative MRI scan, and 3D representations were made using FreeSurfer and Statistical Parametric Mapping software SPM12 with the img_pip package (Fig. 1). ${ }^{7}$ Stimulation was given at a pulse width of 250 $\mu$ sec, pulse duration of 1 second, with square-wave pulses, and at the smallest amplitude that evoked consistent somatosensation during the 25+ stimulations while not resulting in a motor response. The amplitude was $1.5 \mathrm{~mA}$ for $\mathrm{S} 08,2 \mathrm{~mA}$ for S10, and $2 \mathrm{~mA}$ for S14. Dermatomes chosen were the ventral surface of the tip of digit 2 for S08, ventral surface of digit 4 for S10, and the medial surface of digit 5 for S14 (Table 2). Twenty-five trials were completed for S08 and S10 for paradigm 1. For paradigm 2, 50 trials were tested for S10, and 25 trials for S14 (limited by time constraints for testing in the EMU). After testing, the subjects were asked to describe the difference in frequencies. As the magnitude of the frequency of stimulation was increased, the difference in somatosensory percept was described as "faster" (S08), "more intense" (S10), and "faster buzzing" (S14). No subject reported a change in dermatomal area (e.g., larger area) with any of the tested frequencies, or over repeat stimulations. No adverse events occurred during testing.

In paradigm 1, S08 and S10 received cortical stimulation of either 50 or $100 \mathrm{~Hz}$. Stimulation at both frequencies was successful in evoking somatosensory percepts, and the participants were able to correctly differentiate between the frequencies by stating the higher frequency with $98.0 \%$ accuracy (Fig. 2). In paradigm 2, S10 and S14 distinguished between somatosensation arising from cortical stimulation of $2,5,10,20,50$, or $100 \mathrm{~Hz}$. The higher frequency was identified with $73.3 \%$ accuracy (Fig. 2 ). The accuracy of trials testing each frequency pair is broken down in Fig. 3. To evaluate if the first stimulation altered the perception of the second, a comparison was made when the higher frequency was first versus when it was second. When the first frequency was greater than the second $(\mathrm{n}=39)$, the accuracy was $72.2 \%(\mathrm{~S} 10,67.9 \%$; $\mathrm{S} 14$, 90.9\%) compared with $74.4 \%$ (S10, 69.5\%; S14, 76.9\%) when the first frequency was less than the second $(n=36$, $\mathrm{p}>0.99$ ).

Next, to establish the lower limits of detection in an alternating forced-choice paradigm, we compared accuracy at the lower and higher frequencies tested. The accuracy of choosing the higher frequency, broken down by thresholds, is summarized in Fig. 4. The lower limit of accuracy above chance occurs around $20 \mathrm{~Hz}$, where if both frequencies were $20 \mathrm{~Hz}$ or less $(\mathrm{n}=27)$, accuracy was $40.7 \%$ (S10, $33.3 \%$; S14, 55.0\%), while when one frequency was greater than $20 \mathrm{~Hz}$, accuracy increased to $91.7 \%$ (S10, 87.8\%; S14, $100 \% ; \mathrm{n}=48)(\mathrm{p}<0.001)$.

Accuracy decreased significantly when lower frequencies were tested. If both frequencies were less than or equal to $10 \mathrm{~Hz}(\mathrm{n}=12)$, accuracy was $41.7 \%$ compared with $79.4 \%$ when one frequency was greater than $10 \mathrm{~Hz}$ $(n=63, p=0.01)$. Finally, if both frequencies were $50 \mathrm{~Hz}$ or less, accuracy was $59.6 \%(\mathrm{n}=47)$. In trials in which 50 $\mathrm{Hz}$ was the higher frequency $(\mathrm{n}=20)$, accuracy increased to $85 \%$, differing significantly from trials in which $10 \mathrm{~Hz}$ 
S08
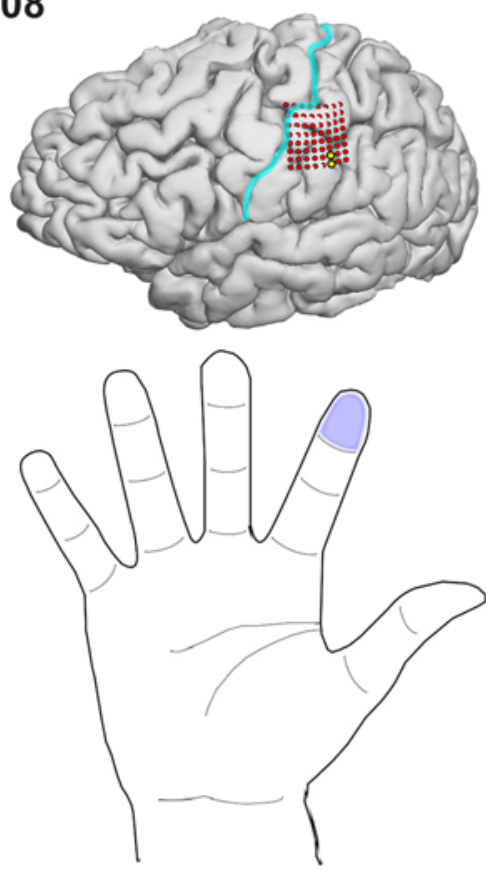

S08
S10
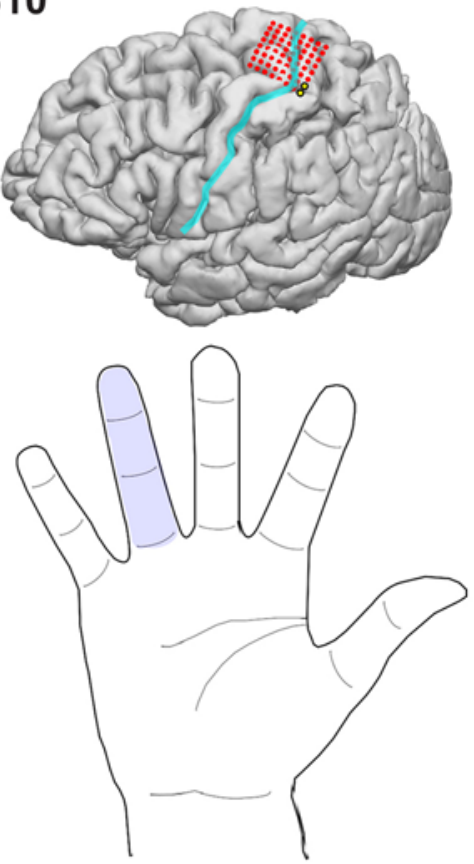

S10
S14
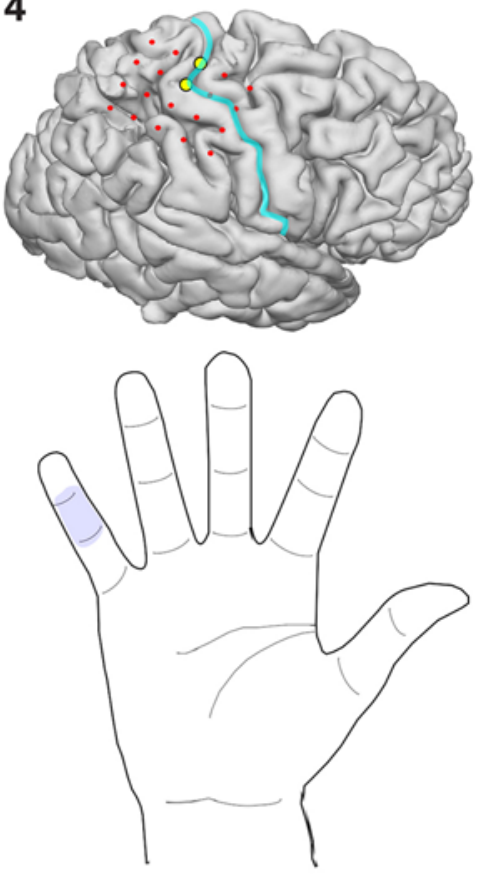

S14

FIG. 1. ECoG grid placement and hand receptive fields. Upper: An ECoG grid was placed over S1 in epilepsy patients. Based on MRI findings, a 3D image was generated of each subject's brain with the electrode grid superimposed. The central sulcus is outlined in green and the electrodes are shown in red. The electrodes chosen for stimulation appear as yellow dots. The electrodes were placed $3 \mathrm{~mm}$ apart in S08 and S10 and $1 \mathrm{~cm}$ apart in S14 (center-to-center). Lower: Dermatomes associated with the chosen electrodes (yellow dots in the upper panel) for stimulation following mapping by an epileptologist.

$(\mathrm{p}<0.05)$ or $20 \mathrm{~Hz}(\mathrm{p}<0.01)$ was the higher frequency. In trials in which $100 \mathrm{~Hz}$ was the higher frequency $(\mathrm{n}=$ 28 ), accuracy was $96.4 \%$, again significantly higher than trials with $10 \mathrm{~Hz}(\mathrm{p}<0.01)$ or $20 \mathrm{~Hz}(\mathrm{p}<0.0001)$ as the higher frequency. There was no significant difference between trials with the higher frequency at $50 \mathrm{~Hz}$ or trials with the higher frequency at $100 \mathrm{~Hz}(\mathrm{p}=0.29)$. Therefore,

\section{TABLE 2. Subjective stimulation qualities}

\begin{tabular}{cccc}
\hline Subject & $\begin{array}{c}\text { Dermatome } \\
\text { Chosen for } \\
\text { Stimulation }\end{array}$ & $\begin{array}{c}\text { Higher-Frequency } \\
\text { Description }\end{array}$ & $\begin{array}{c}\text { Effect of Repeat } \\
\text { Stimulations \& } \\
\text { Larger Frequencies } \\
\text { on Dermatomal Area }\end{array}$ \\
\hline S08 & $\begin{array}{c}\text { Digit 2 ventral } \\
\text { tip }\end{array}$ & "Faster" & No change \\
S10 & $\begin{array}{c}\text { Digit 4 ventral } \\
\text { surface }\end{array}$ & "More intense" & No change \\
S14 & $\begin{array}{c}\text { Digit } 5 \text { medial } \\
\text { surface }\end{array}$ & "Faster buzzing" & No change \\
& & & \\
\hline
\end{tabular}

Dermatomes used for stimulation were chosen on the basis of electrode pairs that elicited safe and reliable somatosensation over a consistent dermatomal area following repeat stimulation by the epileptologist. Subjects reported the subjective quality of percepts arising from higher frequencies. Repeat stimulation and stimulation at larger frequencies did not change the dermatomal area in all subjects. accuracy increased in trials with higher tested frequencies ( $20 \mathrm{~Hz}$ and above), while accuracy was close to chance in trials with lower tested frequencies (10 Hz and below). The greatest accuracy was noted in trials in which one frequency was either 50 or $100 \mathrm{~Hz}$.

Next, we investigated the effect of stimulation differences on accuracy. We isolated and compared trials testing $10 \mathrm{~Hz}$ versus $20 \mathrm{~Hz}$ (frequency difference of $10 \mathrm{~Hz}$ ) and $20 \mathrm{~Hz}$ versus $50 \mathrm{~Hz}$ (frequency difference of $30 \mathrm{~Hz}$ ). When one stimulus was at $10 \mathrm{~Hz}$ and the other was at 20 $\mathrm{Hz}(\mathrm{n}=6)$, accuracy was $16.7 \%$, compared with $85.7 \%$ in trials testing $20 \mathrm{~Hz}$ versus $50 \mathrm{~Hz}(\mathrm{n}=7, \mathrm{p}<0.05)$ (Fig. $5)$. When one frequency was $20 \mathrm{~Hz}$ and the other was 5 $\mathrm{Hz}$ (frequency difference of 15), accuracy was $66.7 \%$ ( $\mathrm{n}=$ $6)$. Overall, summing the low frequency differences, when the difference was less than or equal to $40 \mathrm{~Hz}(\mathrm{n}=39)$, accuracy was $53.9 \%$, compared with $94.4 \%$ accuracy when the difference was greater than $40 \mathrm{~Hz}(\mathrm{n}=39)(\mathrm{p}<0.0001)$ (Fig. 5). Accuracy was above chance at a frequency difference of $30 \mathrm{~Hz}$ or greater.

\section{Discussion}

Here, we investigated the effects of stimulation frequency on the percepts evoked when electrically stimulating the S1. Expanding on previous work, this study sought to establish the plausibility and limitations of us- 


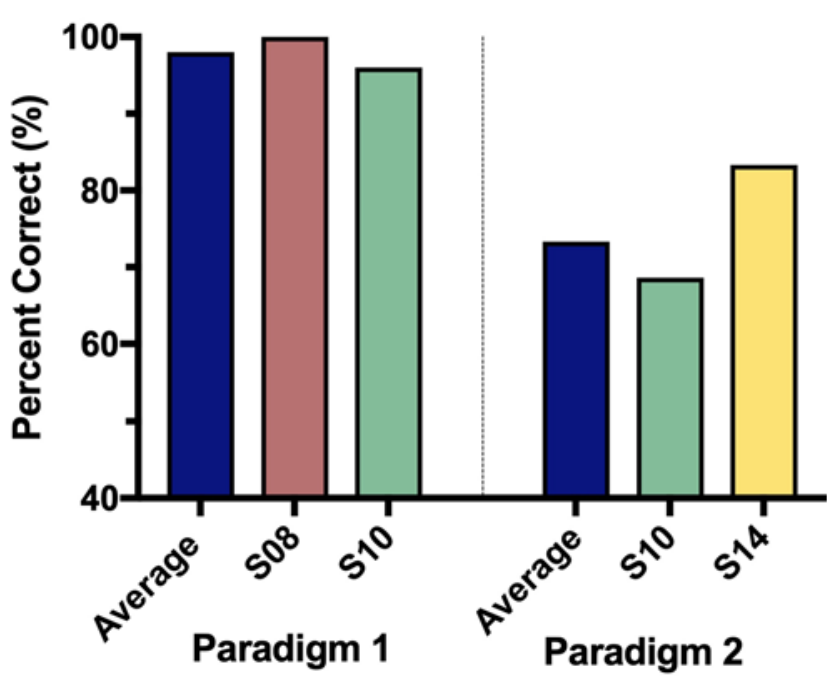

FIG. 2. Accuracy across both paradigms. Paradigm 1 tested frequencies of $50 \mathrm{~Hz}$ and $100 \mathrm{~Hz}$ and had an overall accuracy of $98.0 \%$ (S08, 100\%; $\mathrm{S} 10,96 \%)$. Paradigm 2 tested frequencies of $2,5,10,20,50$, and 100 $\mathrm{Hz}$ and had an overall accuracy of $73.3 \%$ (S10, 68.2\%; S14, 83.3\%).

ing frequency as an adjustable parameter for the sensory component of a closed-loop BCI system. Using ECoG grids over the S1 hand area, we were able to show frequency as a reliable and adjustable component in somatosensory BCI systems. Subjects distinguished between percepts arising from stimuli of 50 and $100 \mathrm{~Hz}$ with nearperfect accuracy, suggesting that frequency may be utilized as a degree of freedom with excellent reliability. In evaluating response accuracy as stimulation frequencies were adjusted over a range of $2-100 \mathrm{~Hz}$, we found that frequencies below $20 \mathrm{~Hz}$ were unreliable, and a system with frequencies spaced out $30 \mathrm{~Hz}$ would lead to reliable detection.

Utilizing frequency as the only altered stimulation parameter, participants were asked to differentiate between two identical targets in a nontactile environment. We were able to show a high degree of accuracy for 50 versus $100 \mathrm{~Hz}(98.0 \%)$. This is not unexpected, as prior work has shown good differentiation of 50, 65, 75, and $100 \mathrm{~Hz}$ in humans ${ }^{9}{ }^{9}$ however, the trial set was limited. We have previously shown that $10-\mathrm{Hz}$ differences are detectable between 20 and $60 \mathrm{~Hz}$ but did not explore lower, or repeat, frequency stimulations to assess the threshold of absolute detection to inform stimulation parameters in BCI. ${ }^{15}$ Here, we show that repetitive stimulation with the same two frequencies is easily distinguishable, suggesting the stability of frequency as a stimulation "degree of freedom" for somatosensory BCI. In the second paradigm, when one stimulus was 50 or $100 \mathrm{~Hz}$, accuracy was $91.7 \%$, compared with $40.7 \%$ when both stimuli were less than or equal to $20 \mathrm{~Hz}$ ( $\mathrm{p}<0.001)$. Although the lower ends $-2,5$, and $10 \mathrm{~Hz}$ - may not have been detected at all, as participants made subjective comments to this effect, when the other frequency was 50 or $100 \mathrm{~Hz}$, the subjects were able to reliably discern between the two frequencies. This may suggest that patients are perceiving some stimuli at lower tested frequencies that are not reaching conscious perception. Another possibility is that the absence of perception at a low frequency leads to the correct identification of the higher frequency by default, as only one stimulus is perceived.

We tested a range of frequencies from 2 to $100 \mathrm{~Hz}$. Our results suggest that $20 \mathrm{~Hz}$ may be a lower limit of detection but not reliable enough to be functionally useful. Accuracy increased significantly (79.4\%) when one tested frequency was $20 \mathrm{~Hz}$ or greater; however, if $20 \mathrm{~Hz}$ was the

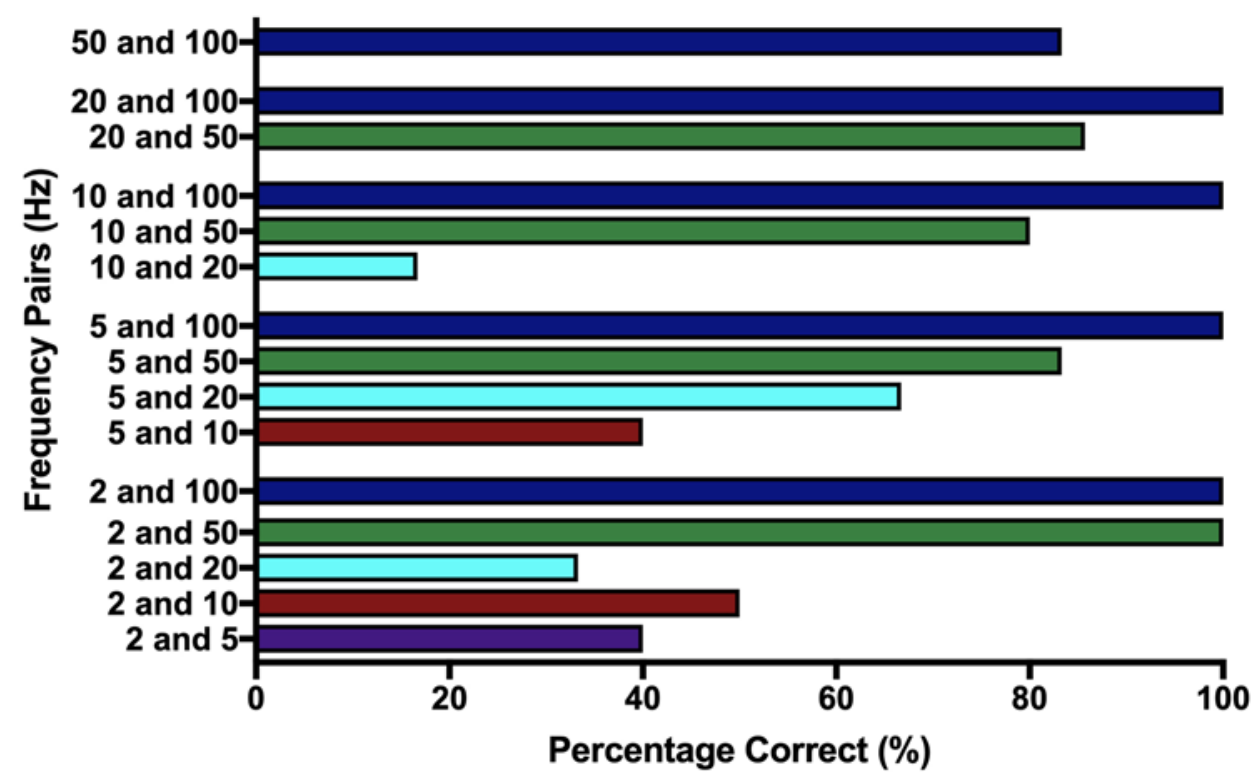

FIG. 3. Correct responses for different frequency pairs. Percentage correct for all trials tested. Accuracy increased when at least one frequency was greater than $20 \mathrm{~Hz}$. 


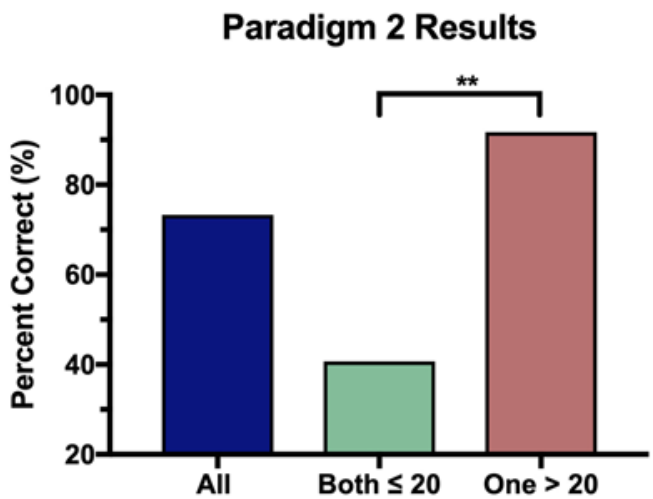

Stimulation Frequencies $(\mathrm{Hz})$

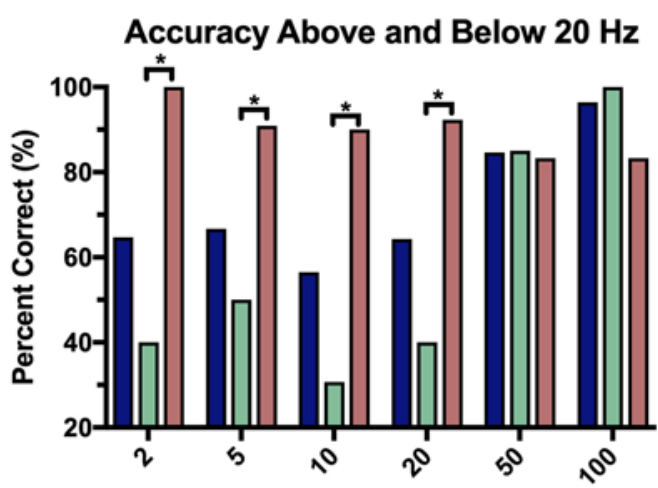

One Stimulation Frequency $(\mathrm{Hz})$

\footnotetext{
Second Stimulation Frequency $(\mathrm{Hz})$

$\square$ All Frequencies

$\square>20$

$\square \leq 20$
}

FIG. 4. Accuracy with frequencies above and below $20 \mathrm{~Hz}$. Left: Accuracy when both tested frequencies were below or equal to $20 \mathrm{~Hz}$ versus when one frequency was above $20 \mathrm{~Hz}$. Accuracy increased substantially when one frequency was above $20 \mathrm{~Hz} c 0 \mathrm{~m}-$ pared with when both frequencies were less than or equal to $20 \mathrm{~Hz}(91.7 \%$ and $40.7 \%$, respectively), giving an overall accuracy of $73.3 \%$. Right: Accuracy at all tested frequencies, when the second frequency was above or below $20 \mathrm{~Hz}$. At lower frequencies $(2$, 5,10 , and $20 \mathrm{~Hz}$ ), accuracy increased greatly when the second tested frequency was above $20 \mathrm{~Hz}$ versus when it was less than or equal to $20 \mathrm{~Hz}$, likely indicating a lack of perception below $20 \mathrm{~Hz}$. At 50 and $100 \mathrm{~Hz}$, there was little effect on accuracy when the second frequency was greater than $20 \mathrm{~Hz}$ compared with less than or equal to $20 \mathrm{~Hz}$. ${ }^{*} \mathrm{p}<0.05$; ${ }^{* *} \mathrm{p}<0.001$.

higher frequency, accuracy was around chance (42.9\%). Accuracy rose to $85 \%$ when one tested frequency was 50 $\mathrm{Hz}$ or greater. These findings are in agreement with our previous work using ECoG, in which the majority (56\%) of participants first reported a sensation with $20-\mathrm{Hz}$ stimu- lations. ${ }^{16}$ In NHP microstimulation trials, monkeys were able to perceive and discern between stimulations as low as $10 \mathrm{~Hz}$, suggesting that reliable somatosensation occurs at or below $10 \mathrm{~Hz} .{ }^{22}$ Our results indicate that stimulation below $20 \mathrm{~Hz}$ is not reliable. This discrepancy could result
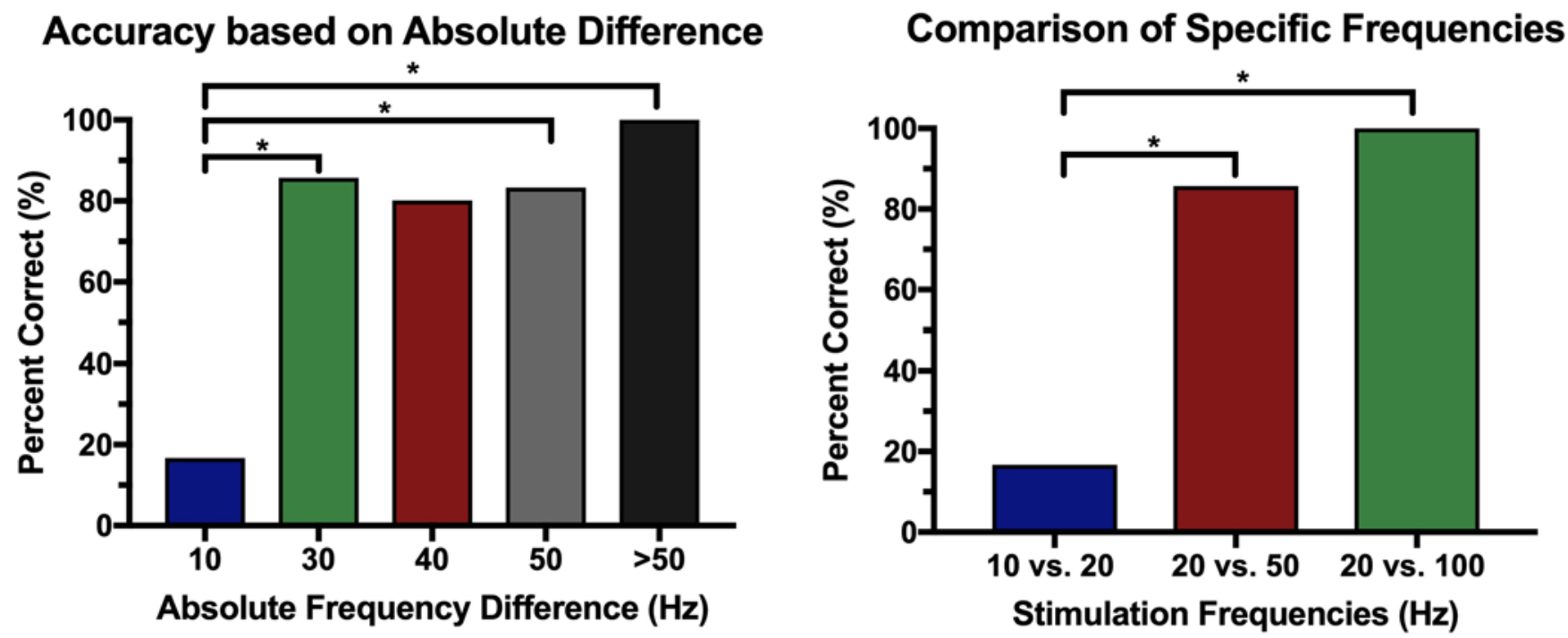

FIG. 5. Accuracy at tested frequencies organized by the absolute difference between the two. Left: Accuracy based on the absolute difference between tested frequencies. Accuracy increased when the frequency difference was $30 \mathrm{~Hz}$ or greater compared with $10 \mathrm{~Hz}$. Right: Accuracy at specific frequencies. Trials in which the tested frequencies were 10 versus $20 \mathrm{~Hz}, 20$ versus $50 \mathrm{~Hz}$, and 20 versus $100 \mathrm{~Hz}$ were isolated and compared. Accuracy was low in trials testing 10 versus $20 \mathrm{~Hz}$ and increased significantly in trials testing 20 versus $50 \mathrm{~Hz}$ and 20 versus $100 \mathrm{~Hz} .{ }^{*} p<0.05$. 
from a difference in species, study designs, stimulation devices, or all the above. We have previously suggested that high-density ECoG is a less-invasive approach to accessing more of the existing architecture in $\mathrm{S} 1 .^{14}$ These results suggest that even if the stimulation parameters are less easily differentiated with ECoG compared with microelectrodes, detecting differences is still reliable and feasible in a relatively large range of acceptable stimulation parameters (20 to $100 \mathrm{~Hz}$ ). ${ }^{1,21,25,29}$

Our findings suggest that reliable differentiation between frequencies may occur when the frequency difference is at least $30 \mathrm{~Hz}$. We found that a frequency difference of $10 \mathrm{~Hz}$ led to a poor accuracy of $16.7 \%$, whereas a frequency difference of $30 \mathrm{~Hz}$ led to a greatly improved accuracy of $85.7 \%$. Previously, we have shown that a 10 $\mathrm{Hz}$ difference, between 20 and $100 \mathrm{~Hz}$, is detected above chance, ${ }^{15}$ however, here $10 \mathrm{~Hz}$ or smaller differences occurred at lower tested frequencies $(2,5,10$, or $20 \mathrm{~Hz}$ ). These results likely reflect a lower detection threshold of around $20 \mathrm{~Hz}$, rather than a just-noticeable difference. The low accuracy in trials testing $10 \mathrm{~Hz}$ versus $20 \mathrm{~Hz}(16.7 \%)$ indicates that participants reliably chose $10 \mathrm{~Hz}$ as the higher frequency; however, when only comparing $10 \mathrm{~Hz}$ and $20 \mathrm{~Hz}$, the trial numbers were small $(\mathrm{n}=6)$. Perhaps it reflects a reversal of somatosensation in this frequency range, but this hypothesis warrants further investigation.

Subjectively, we asked participants to describe the sensations comparing 2 frequencies. Across both paradigms, when both frequencies were perceived, the higher frequency was described as "faster" (S08), "more intense" (S10), and "faster buzzing" (S14), in line with previous studies (Table 2)..$^{8,9,16}$ Below $20 \mathrm{~Hz}$, subjects did not report somatosensation, and at $20 \mathrm{~Hz}$, they described the stimulation as "inconsistent." Repeat stimulations and larger frequencies did not alter the dermatomal region that exhibited percepts (Table 2). This adds to our previous report establishing broad, unnatural feeling percepts from stimulation ${ }^{16}$ and suggests more clearly that the speed of stimulation frequency is translated to the perception.

This study has several limitations. The sample size in each paradigm was limited to 2 participants, making the results difficult to generalize. The trials were performed in the EMU, limiting control and requiring clinical and time constraints, ultimately preventing more trials and paradigms. In addition, other stimulation parameters, such as amplitude, varied between participants, possibly making comparisons between subjects unreliable. We chose to keep the amplitude as low as possible while maintaining reliable detection (25 trials at the chosen amplitude and 50 $\mathrm{Hz}$ ), but this may have introduced differences in responses. The subjects were diagnosed with epilepsy, a disease that may remodel cortical pathways in S1. However, they experienced consistent somatosensation in a localized region and had no known pathology affecting the hand representation of S1. The location on S1 was not consistent between subjects (i.e., location of percepts on the hand) due to variability in grid placement. It is possible that a difference in cortical or dermatomal representations of the areas used alters perception of cortical stimulation. Finally, the results of this study are not representative of chronic stimulation and its effects, as each session took place in 1 day.

\section{Conclusions}

We investigated the frequency component of cortical stimulation to understand the limitations, parameters, and plausibility of using this component as a degree of freedom in somatosensory BCI. We report frequency as a reliable stimulation parameter in ECoG-generated somatosensation, with near-perfect accuracy on multiple trials of 50 versus $100 \mathrm{~Hz}$. Our results also imply a lower limit of detection around $20 \mathrm{~Hz}$ and suggest that a lower limit for reliable sensation occurs in the range between $20 \mathrm{~Hz}$ and $50 \mathrm{~Hz}$. Thus, we suggest that frequencies larger than $20 \mathrm{~Hz}$ can be utilized as an adjustable parameter to evoke reliable, unique, distinguishable somatosensation.

\section{Acknowledgments}

This study was funded by a grant awarded to D.R.K. through the National Institutes of Health (grant no. R25 NS099008-01). This study was also supported by Cal-BRAIN: A Neurotechnology Program for California, National Center for Advancing Translational Science (NCATS) of the National Institutes of Health (grant no. KL2TR001854), the Neurosurgery Research and Education Foundation (NREF), the Tianqiao and Chrissy Chen Brain-Machine Interface Center at Caltech, the Boswell Foundation, and the Della Martin Foundation.

\section{References}

1. Agnew WF, McCreery DB: Considerations for safety in the use of extracranial stimulation for motor evoked potentials. Neurosurgery 20:143-147, 1987

2. Armenta Salas M, Bashford L, Kellis S, Jafari M, Jo H, Kramer D, et al: Proprioceptive and cutaneous sensations in humans elicited by intracortical microstimulation. eLife 7:e32904, 2018

3. Bensmaia SJ, Miller LE: Restoring sensorimotor function through intracortical interfaces: progress and looming challenges. Nat Rev Neurosci 15:313-325, 2014

4. Dadarlat MC, O'Doherty JE, Sabes PN: A learning-based approach to artificial sensory feedback leads to optimal integration. Nat Neurosci 18:138-144, 2015

5. Flesher SN, Collinger JL, Foldes ST, Weiss JM, Downey JE, Tyler-Kabara EC, et al: Intracortical microstimulation of human somatosensory cortex. Sci Transl Med 8:361ra141, 2016

6. Fridman GY, Blair HT, Blaisdell AP, Judy JW: Perceived intensity of somatosensory cortical electrical stimulation. Exp Brain Res 203:499-515, 2010

7. Hamilton LS, Chang DL, Lee MB, Chang EF: Semi-automated anatomical labeling and inter-subject warping of highdensity intracranial recording electrodes in electrocorticography. Front Neuroinform 11:62, 2017

8. Hiremath SV, Tyler-Kabara EC, Wheeler JJ, Moran DW, Gaunt RA, Collinger JL, et al: Human perception of electrical stimulation on the surface of somatosensory cortex. PLoS One 12:e0176020, 2017

9. Johnson LA, Wander JD, Sarma D, Su DK, Fetz EE, Ojemann JG: Direct electrical stimulation of the somatosensory cortex in humans using electrocorticography electrodes: a qualitative and quantitative report. J Neural Eng 10:036021, 2013

10. Kim S, Callier T, Tabot GA, Gaunt RA, Tenore FV, Bensmaia SJ: Behavioral assessment of sensitivity to intracortical microstimulation of primate somatosensory cortex. Proc Natl Acad Sci U S A 112:15202-15207, 2015

11. Kim S, Callier T, Tabot GA, Tenore FV, Bensmaia SJ: Sensitivity to microstimulation of somatosensory cortex distributed over multiple electrodes. Front Syst Neurosci 9:47, 2015 
12. Klaes C, Shi Y, Kellis S, Minxha J, Revechkis B, Andersen RA: A cognitive neuroprosthetic that uses cortical stimulation for somatosensory feedback. J Neural Eng 11:056024, 2014

13. Kramer DR, Barbaro MF, Lee M, Peng T, Nune G, Liu CY, et al: Electrocorticographic changes in field potentials following natural somatosensory percepts in humans. Exp Brain Res 237:1155-1167, 2019

14. Kramer DR, Kellis S, Barbaro M, Salas MA, Nune G, Liu $\mathrm{CY}$, et al: Technical considerations for generating somatosensation via cortical stimulation in a closed-loop sensory/motor brain-computer interface system in humans. J Clin Neurosci 63:116-121, 2019

15. Kramer DR, Lamorie-Foote K, Barbaro M, Lee M, Peng T, Gogia A, et al: Functional frequency discrimination from cortical somatosensory stimulation in humans. Front Neurosci 13:832, 2019

16. Lee B, Kramer D, Armenta Salas M, Kellis S, Brown D, Dobreva T, et al: Engineering artificial somatosensation through cortical stimulation in humans. Front Syst Neurosci 12:24, 2018

17. Liu Y, Rouiller EM: Mechanisms of recovery of dexterity following unilateral lesion of the sensorimotor cortex in adult monkeys. Exp Brain Res 128:149-159, 1999

18. O'Doherty JE, Lebedev MA, Hanson TL, Fitzsimmons NA, Nicolelis MA: A brain-machine interface instructed by direct intracortical microstimulation. Front Integr Nuerosci 3:20, 2009

19. O'Doherty JE, Lebedev MA, Ifft PJ, Zhuang KZ, Shokur $\mathrm{S}$, Bleuler $\mathrm{H}$, et al: Active tactile exploration using a brainmachine-brain interface. Nature 479:228-231, 2011

20. O’Doherty JE, Lebedev MA, Li Z, Nicolelis MA: Virtual active touch using randomly patterned intracortical microstimulation. IEEE Trans Neural Syst Rehabil Eng 20:85-93, 2012

21. Ray PG, Meador KJ, Smith JR, Wheless JW, Sittenfeld M, Clifton GL: Physiology of perception: cortical stimulation and recording in humans. Neurology 52:1044-1049, 1999

22. Romo R, Hernández A, Zainos A, Brody CD, Lemus L: Sensing without touching: psychophysical performance based on cortical microstimulation. Neuron 26:273-278, 2000

23. Romo R, Hernández A, Zainos A, Salinas E: Somatosensory discrimination based on cortical microstimulation. Nature 392:387-390, 1998

24. Sainburg RL, Ghilardi MF, Poizner H, Ghez C: Control of limb dynamics in normal subjects and patients without proprioception. J Neurophysiol 73:820-835, 1995
25. Signorelli F, Guyotat J, Mottolese C, Schneider F, D’Acunzi $\mathrm{G}$, Isnard J: Intraoperative electrical stimulation mapping as an aid for surgery of intracranial lesions involving motor areas in children. Childs Nerv Syst 20:420-426, 2004

26. Suminski AJ, Tkach DC, Fagg AH, Hatsopoulos NG: Incorporating feedback from multiple sensory modalities enhances brain-machine interface control. J Neurosci 30:16777-16787, 2010

27. Tabot GA, Dammann JF, Berg JA, Tenore FV, Boback JL, Vogelstein RJ, et al: Restoring the sense of touch with a prosthetic hand through a brain interface. Proc Natl Acad Sci U S A 110:18279-18284, 2013

28. Tabot GA, Kim SS, Winberry JE, Bensmaia SJ: Restoring tactile and proprioceptive sensation through a brain interface. Neurobiol Dis 83:191-198, 2015

29. Wyllie E, Lüders H, Morris HH III, Lesser RP, Dinner DS, Rothner AD, et al: Subdural electrodes in the evaluation for epilepsy surgery in children and adults. Neuropediatrics 19:80-86, 1988

\section{Disclosures}

The authors report no conflict of interest concerning the materials or methods used in this study or the findings specified in this paper.

\section{Author Contributions}

Conception and design: Kramer, Liu, Kellis, Lee. Acquisition of data: Kramer. Analysis and interpretation of data: Kramer, Lamorie-Foote. Drafting the article: Kramer, Lamorie-Foote. Critically revising the article: all authors. Reviewed submitted version of manuscript: all authors. Statistical analysis: all authors. Study supervision: Kramer, Nune, Liu, Kellis, Lee.

\section{Supplemental Information \\ Previous Presentations}

Portions of this work were presented in abstract form at the 2016 North American Neuromodulation Society Meeting, Baltimore, Maryland, June 25-29, 2016.

\section{Correspondence}

Daniel R. Kramer: University of Southern California, Los Angeles, CA.dankramer29@gmail.com. 